\title{
Raquialgias: Modelos Fisioterapêuticos e Preventivos
}

\section{Back Pain: Physiotherapeutic and Preventive Models}

Luís Coelho ${ }^{1}$

PALAVRAS-CHAVE: Dor nas Costas; Modalidades de Fisioterapia; Postura

KEYWORDS: Back Pain; Physical Therapy Modalities; Posture

As raquialgias não são, somente, a condição mais usual de atendimento em Fisioterapia. O seu trato, avaliativo e interventivo, constitui a imagem de um "estado de arte" clínico e epistemológico da profissão. Assim, numa perspetiva mormente fisioterapêutica, são duas, as causas principais de raquialgia, com diferentes implicações: uma causa "posterior", postural, e uma causa funcional, frequentemente "discal".

A causa postural tem uma importância essencialmente miofascial e, até, neuromotora, envolvendo, especialmente, a musculatura posterior, fortemente "tónica", que, de acordo com o paradigma das cadeias musculares, ${ }^{1-5}$ é quase sempre excessivamente resistente, propendendo às alterações posturais. Esta causalidade propugna um modelo "estrutural" e de "longo prazo", implicando um trabalho centrado, fundamentalmente, no alongamento dos tecidos moles, em flexão.
A causa funcional é frequentemente "discal", exigindo, muitas vezes, uma intervenção em extensão, que permita precipitar a reabsorção do núcleo pulposo do disco inter-vertebral.

Os mecanismos referidos não precisam de excluir-se entre si, com o processo discal a poder ser consequente à retração posterior, ou a poder provocá-la (cada modelo dirá ser "causal" face ao processo considerado subsidiário). Nem sempre é possível conceber a correta ordem nosológica e anamnésica, no entanto, os dois mecanismos não são necessariamente compatíveis nas implicações do tratamento. Isto porque o trabalho postural/em flexão pode agravar o quadro discal, incluindo a cervico-braquialgia e/ou a lombo-ciatalgia, enquanto que o trabalho em "extensão" tende a ser deplorado pelo primeiro. 
A defesa do modelo "estrutural" é comummente paradigmática, assaz dogmática, valorizando aspetos racionais, eventualmente "ideais"; ela rejeita, muitas vezes, o modelo "funcional", mais de acordo com o paradigma empírico. Cabe, aqui, contrapor, também, a necessidade de uma casuística longitudinal à dos estudos nomotéticos que, bastas vezes, não são sensíveis ao conjunto das múltiplas variáveis associadas ao indivíduo. Para o paradigma "postural", o modelo empírico limitar-se-á a revelar aspetos "locais", ignorando a causa profunda da problemática, que tende a considerar como "desenvolvimental".

É a experiência casuística que tem demonstrado ser possível compatibilizar os dois modelos: a intervenção primariamente "postural" não deve, no entanto, forçar determinadas posturas, mas, sim, preparar a fase seguinte (abrangendo o movimento), que não precisa de incluir o reforço da musculatura posterior, a não ser, claro, a abdominal profunda, mediante a aplicação de Pilates ou abdominais hipopressivos. Estas e outras atividades - como o treino do equilíbrio e controlo motor - podem e devem ser adequadas à especificidade do paciente, incluindo as terapêuticas manuais, 3,4 Trata-se, portanto, de usar, constantemente, o tratamento enquanto via de exploração nosológica, com coordenação da dupla vertente teorética e científica. $\bigcirc$ que, em última análise, desaconselha as intervenções grupais e a prescrição de desportos, que se limitam a reforçar de modo indiscriminado o corpo, podendo prejudicar o equilíbrio muscular. De igual modo, intervenções massificadas de controlo meramente anti-sintomático limitam-se, tão-só, a perpetuar a condição prévia. Por outro lado, também se desaconselha a higiene postural, capaz de criar ansiedade. Ela tem-se submetido aos modelos funcionais, que se adaptam, sobretudo, a grupos. A intervenção "individual" que permite a equilibração, espontânea e não forçada, dos modelos segundo o sentido "alongamento - mobilidade - fortalecimento"3,4 parece ser mais efetiva na própria prevenção do que a indução de "normas" posturais que apenas se limitam a forçar conscientemente músculos de controlo fortemente inconsciente. ${ }^{6}$ Esta é outra razão pela qual o clássico fortalecimento da musculatura posterior deve ser comutado pela reequilibração entre a zona "posterior" hegemónica (e, portanto, fraca, aquando da tensão excessiva7,8) e a "anterior" geralmente mais fraca. Só depois de ser esgotado o processo "postural", deve o indivíduo ser encarado empiricamente com o objetivo de debelar, mais especificamente, a sintomatologia.

\section{RESPONSABILIDADES ÉTICAS}

CONFLITOS DE INTERESSE: Os autores declaram não possuir conflitos de interesse.

SUPORTE FINANCEIRO: O presente trabalho não foi suportado por nenhum subsídio ou bolsa.

PROVENIÊNCIA E REVISÃO POR PARES: Não comissionado; revisão externa por pares.

\section{ETHICAL DISCLOSURES}

CONFLICTS OF INTEREST: The authors have no conflicts of interest to declare.

FINANCIAL SUPPORT: This work has not received any contribution grant or scholarship.

PROVENANCE AND PEER REVIEW: Not commissioned; externally peer reviewed.

\section{REFERÊNCIAS}

1. Mézières F. La gymnastique statique. Paris: Vuibert; 1947.

2. Mézières F. La révolution en gymnastique orthopédique. Paris: Vuibert; 1949

3. Coelho L. O método Mézières ou a revolução na ginástica ortopédica: O manifesto anti-desportivo ou a nova metodologia de treino. Motricidade. 2008; 4: 21-39.

4. Coelho, L. O anti-fitness ou o manifesto anti-desportivo. Introdução ao conceito de reeducação postural. Quinta do Conde: Contra-Margem; 2008.

5. Coelho L. Mézières' method and muscular chains' theory: from postural re-education's physiotherapy to anti-fitness concept. Acta Reumatol Port. 2010; 35: 406-7.

6. Bienfait M. Os desequilíbrios estáticos: fisiologia, patologia e tratamento fisioterápico. São Paulo: Summus editora; 1995.

7. Souchard Ph-E. Le champs clos. Paris: Maloine; 1981.

8. Nisand M. La méthode Mézières: un concept révolutionnaire. Paris: Éditions Josette Lyon; 2006. 